\title{
DESIGNING YOUR ENGINEERING CAREER: THE APPLICATION OF THE DESIGN PROCESS TO CAREER DEVELOPMENT
}

\author{
Dr. Sean O'Brien and Carolyn Geddert \\ University of Manitoba - Faculty of Engineering \\ Sean.OBrien@umanitoba.ca ; Carolyn.Geddert@umanitoba.ca
}

\begin{abstract}
Students have often reported feeling unprepared for career planning, development and decision-making. The open-ended nature of career development may be analogous to the design space, and may therefore benefit from the application of the engineering design process. This teaching practice report discusses the authors' experience implementing a seminar in an engineering program, which guides students to apply the engineering design process to their career development. The application of the design process to student career development may improve students' confidence and success by reframing the problem into a structure that they are already proficient with.
\end{abstract}

Keywords: Career Planning, Career Development, Cooperative Education, Industrial Internship, Design Process, Engineering Education

\section{INTRODUCTION}

Post-secondary education is still often thought to be a guarantee of employment. This myth developed from previous eras when only a small portion of the population pursued post-secondary education and usually with the encouragement of an entire community. The increase in enrollment in post-secondary education, more than 6 fold from 1951-1975 [1] has made the post-graduation employment open to a less defined path. Career development is a process that applies to all students and can cause negative stress. The number of variables in a quickly changing world economy, with many factors contributing to the direction for growth or change, create difficulties in determining clear pathways for success. There are many pathways available, some clear and others not visible. Regardless, their outcomes are not obvious. This "decision explosion" is a daunting and open-ended problem, and unlike the academic path, is filled with uncertainty that can cause mental and emotional stress and unhappiness [2].

Fortunately, the engineering design process may be well suited to the open-ended and ambiguous challenge of career development, as recommended by Burnett and Evans in the recently published book "Designing your Life" [2]. Engineering students who are acquainted with and have expertise with the design process can use it as an effective tool to instill confidence for a positive outcome. The confidence or hope for a positive outcome can be an essential component in its realization [3].

A common model for career development can be found at many Canadian university campuses. As a first step, University of Manitoba engineering students are presented with an opportunity to identify skills and build competencies in some of their early years' courses. This can involve a mapping of CEAB defined Graduate Attributes to employability skills and identifying opportunities for experiences that enhance employability [4]. In later years, support is provided for job search, networking, as well as self-marketing techniques and materials. Although somewhat customized for engineering students for this discussion, the basics of this approach would be considered for use throughout the university. The addition of the engineering design process to these career development components allows for increased opportunity for confidence in the process and ultimately improved outcomes.

\section{METHODS}

The approach of using the design process for career development was taught to graduate engineering students in a one hour seminar. Students then completed a questionnaire to provide some preliminary feedback regarding the seminar and the approach. Within the career development seminar, the similarities between engineering design problems and career development were emphasized, and the application of the design process to career development was demonstrated. Within the seminar, it was also explained that this is not a sequential process, nor is the process ever complete, since career development is a lifelong activity. 


\subsection{Career Planning Seminar}

The following sections summarize the content that was taught to graduate engineering students in the career planning seminar. The design process was discussed in terms of the following components: Defining the Problem, Gathering Information, Concept Development and Selection, Design Development and Implementation. Each section below covers a component of the design process, as well as an explanation of how it can be applied to career development.

\subsubsection{Defining the Problem}

Students have often reported that their career development strategy after graduation included quickly choosing a field of work (for example: aerospace structure design), followed by waiting for a job to appear on online job postings in their chosen field of work and applying. Many students had previously reported that they only viewed the problem definition of career development as finding a job in online job postings within the narrow, yet often poorly defined, field of work that they had chosen. For the application of the design process to overall engineering career development, it is recommended by Burnett and Evans [2] that everyone begins with considering the questions "Why do you work?" and "What is your world view?". These two questions were intended to explore issues around the much broader problem of career development rather then simply finding a new job. The answers to the first question may include things such as: for financial income, to make a difference in the world, for the enjoyment of overcoming a challenge, the enjoyment of interacting with other people and many others. These answers should lead towards identifying the type of work that each person enjoys and should help identify the types of work that would be satisfying to each individual. The second question regarding the world view of each person is intended to ensure that each individual gives thought to what they feel most strongly about to ensure that the career path they develop is consistent with their view of what is important to them.

The answers to these two questions can then be used to develop career objectives. It is important to note that this will lead to a problem definition with a much broader scope then choosing a general field of practice (such as aerospace structure design) and then looking for job postings within that field.

Finally, the problem definition must include consideration of the constraints. As with product development, the constraints within career development will include anything which may limit the possible solutions to the career development problem. These constraints may include a necessary minimum salary, geographical location limitations and others.
As with any design problem, as time progresses your knowledge of the challenge increases while your design freedom decreases. As a result, it is important that longterm career goals remain broad enough so as not to prematurely limit your design freedom of career opportunities before you have a greater amount of knowledge about the challenge. Some students have reported that they remained unemployed for a period of time after graduation because their target (ideal) job had not been posted online and they were waiting for the perfect opportunity. In the design process it is generally recognized that any design or product can be improved, and similarly any career can likely be improved. Therefore, it is important to recognize that an "ideal" job most likely does not exist. A career must be "developed", rather than "received". For this reason, it is essential that individuals properly define the problem in terms of career objectives and constraints, rather than waiting to receive their poorly defined "ideal" job.

\subsubsection{Gathering Information}

Many students reported that they assumed that no additional information was available to them or necessary beyond their existing limited knowledge and impressions of possible career options at the time of graduation. As a result, gathering information may be a step that is often skipped and yet is necessary to making good decisions about career development. Within the seminar, students were provided with several sources for information. These information sources included reviewing job postings over a period of time, gathering information from technical organizations and having discussions with those knowledgeable about their areas of interest. These will also be discussed in greater detail below. It was emphasized within the seminar that job postings should be reviewed over a substantial period of time, long before looking for your next job, in order to become familiar with the typical availability of specific job types. Gathering information from technical organizations, through discussions, as well as from additional sources, will be discussed in detail in the following sections.

\subsubsection{Concept Development and Selection}

Within the context of product development and the design process, students should be aware that your first concept is usually not your best and that brainstorming, as well as other concept generation techniques, should be utilized to develop a large quantity of possible designs. Similarly, it is important to spend time generating possible concepts for career development, so that the best alternative can be selected and so that individuals can be proactive in developing their careers.

Additionally, it is important that individuals prototype their ideas to inform their decisions of which career 
concepts are worth pursuing further and which career concepts are unlikely to fulfil their objectives. One excellent method of prototyping career concepts would be through cooperative education and internship programs. Cooperative education and internship programs present a great opportunity for students to experience career options, observe the workplace environment and the roles of others within the organization, as well as develop their own skills and experience with only a short-term commitment.

There are also many other opportunities to prototype ideas outside of cooperative education and internship programs, which will enable students to gather additional information that is more specific than the information that they would have gathered previously and possibly acquire direct feedback on their ideas. Opportunities for this include attending the many presentations at the university campus from representatives from the companies or industries they are interested in and having discussions with these representatives. Also, conferences, technical meetings, and networking events run by the university, the professional association, technical associations and other groups are a great opportunity to gather specific information about career options. Furthermore, students could contact a specific individual or company that they are interested in to ask for a meeting to find out about how a specific individual developed a successful career, what their career is like, and what they can do to prepare themselves for a career in a similar area. Some students may feel uncomfortable asking others for career advice, however, the observation of the authors has been that most people appear to be honored by the request to share their career story and knowledge. All of these prototyping opportunities involve networking, and there are also many other networking opportunities that should be considered. Networking is essential for career development and is important for gathering information, prototyping career concepts, as well as developing and implementing a career design as discussed in the following section.

It is important that a well thought out selection criteria be established in order to objectively select the concepts that are worthy of further investigation and final selection. The selection criteria will depend upon the individualized objectives and constraints set earlier in the process. Students were also encouraged to consider career paths through the visualization of an objective tree to aid their decision-making. Career paths with many branched options, including some which have a high probability of success, may be more likely to meet career objectives than paths with low probabilities and few alternative opportunities for success without requiring the total rework of their experience and career plans.

\subsubsection{Design Development and Implementation}

Design development and implementation involve taking the next step in career development and finding your next job. Students were reminded that online job postings may only represent $20 \%$ of the job market [2]. Furthermore, of the $20 \%$ of jobs that are posted online, many of the jobs may have already been filled and have only been posted to fulfill a corporate policy [2]. The majority of jobs may therefore exist in the "hidden" job market, which operates based on referrals. The reason for this is that there may be a large risk for companies and hiring managers to hire a completely unknown applicant. Often the risk of hiring the wrong person (such as someone who is the most qualified yet is not a reliable team player), may be greater than the opportunity of hiring the most qualified person. For this reason, the majority of jobs may go to candidates who are known to the hiring managers from outside of the current job search context. As a result, networking is vital to career success. Fortunately, all of the networking performed in the preceding sections will have prepared individuals to find their future jobs and can give them access to the hidden job market [2].

Additionally, luck and risk must be proactively managed throughout the entire process. Just as with risk management within design and product development, positive and negative risks must be actively monitored and controlled within career development. Many students may perceive that someone who was offered an unposted job got lucky by being in the right place at the right time and having the right person in their network. However, opportunities through networking are a critical component to career development strategy and must be actively pursued. Although only a small proportion of network connections may lead to a job offer, building a large network with a strong presence within that network can result in valuable opportunities.

It is important to remember once again that opportunities should be evaluated in terms of whether the opportunity is a step in the right direction for an individual's career, rather than whether a job is the "ideal" job for the individual. As discussed previously, an "ideal" job may not exist and most likely could not be recognized based on the limited information of a job posting.

Finally, career development is a lifelong undertaking. Once a new job has been obtained, it is important that attention is returned to reassessment, and continuing to go through the design process again to further develop and advance a career. It is important that individuals should begin planning and developing their career immediately (and not wait for graduation), as well as avoid getting stuck by showing a bias towards action so that they are always proactively controlling the future of their career and continuously improving. 
Table 1: Questionnaire statements for engineering graduate students who attended the career development seminar (statements were responded to using a five point Likert scale).

\begin{tabular}{|l|l|}
\hline $\begin{array}{c}\text { Statement } \\
\text { Number }\end{array}$ & \multicolumn{1}{c|}{ Statement } \\
\hline 1 & I believe that my career plans were very well developed prior to this seminar. \\
\hline 2 & $\begin{array}{l}\text { I am considering making changes to my career development strategy as a result of } \\
\text { attending this seminar. }\end{array}$ \\
\hline 3 & I am considering using the design process for my career planning and development. \\
\hline 4 & I have found the seminar to be engaging and stimulating. \\
\hline 5 & I have learned something which I consider valuable. \\
\hline
\end{tabular}

\subsection{Assessment of Seminar Impact}

The approach of using the design process for career development was taught as an optional one hour seminar to engineering graduate students at the University of Manitoba. Twelve students participated in the seminar. As a preliminary evaluation of the short-term student response to the career development seminar, the students completed a questionnaire. The questionnaire included five statements (Table 1) which were rated on a five-point Likert scale (strongly disagree, disagree, neutral, agree and strongly agree). The questionnaire also included a comments section regarding what the students liked about the seminar and how the seminar could be improved.

\section{RESULTS AND DISCUSSION}

The approach of using the design process for career development was taught in a seminar for engineering graduate students and feedback was obtained using a questionnaire. The results of the questionnaire are shown in Table 2 and Figure 1.

The results indicated that the majority of students in attendance may not have been confident that their career plans were well developed prior to the seminar $(25 \%$ disagree and $58 \%$ neutral). The majority of students indicated that they were considering using the design process for their career planning and development after attending the seminar (67\% agree and 17\% strongly agree). Meanwhile, every student in attendance indicated that they learned something which they considered valuable $(50 \%$ agree and $50 \%$ strongly agree). The comments on the questionnaire were also very positive. These preliminary results provide an indication of how readily students may adopt this approach.

A larger sample size of students, with a more rigorous follow-up over a period of time would be required to fully evaluate the potential benefits of this approach. However, these preliminary results are encouraging and do warrant the further investigation of the potential benefits of teaching students to apply the design process to their career development. In the future, the Cooperative Education and Industrial Internship program at the University of Manitoba is considering offering this seminar to all engineering undergraduate students in the cooperative education program, in addition to continuing to offer this seminar to graduate students. It is anticipated that offering this seminar could empower students to be more proactive in controlling their own career development. The structure of the design process is very well suited to handling openended problems such as career development. Additionally the familiarity of the design process to engineering students should improve student confidence and self-efficacy in career development.

\section{CONCLUSION}

Students have previously reported feeling unprepared for career planning and development. The open-ended nature and broad range of possibilities of career development can make career development a very challenging problem. However, the engineering design process may be well suited to career planning and development, since the design process is well suited to address open-ended problems. Additionally, engineering students may approach career planning and development with greater confidence, hope and a more proactive attitude by using the engineering design process they are already familiar and proficient with. The application of the design processes to career development was taught to engineering graduate students in a seminar and preliminary feedback was collected. The preliminary results demonstrate a positive response to the approach. The potential benefits and the positive preliminary results of this study, warrant the further investigation of the impact that the application of the design process to career development could have on the engineering careers of students. The application of the design process to career development may help enable engineering students to maximize their career potential. 
Table 2: Questionnaire responses from engineering graduate students who attended the career development seminar (questionnaire statements are shown in Table 1).

\begin{tabular}{|r|r|r|r|r|r|}
\hline \multirow{2}{*}{$\begin{array}{c}\text { Statement } \\
\text { Number }\end{array}$} & \multicolumn{5}{|c|}{ Statement Responses (\%) } \\
\cline { 2 - 6 } & $\begin{array}{c}\text { Strongly } \\
\text { Disagree }\end{array}$ & Disagree & Neutral & \multicolumn{1}{c|}{ Agree } & $\begin{array}{c}\text { Strongly } \\
\text { Agree }\end{array}$ \\
\hline 1 & & $25 \%$ & $58 \%$ & $17 \%$ & \\
\hline 2 & & & $17 \%$ & $67 \%$ & $17 \%$ \\
\hline 3 & & & $17 \%$ & $67 \%$ & $17 \%$ \\
\hline 4 & & & & $67 \%$ & $33 \%$ \\
\hline 5 & & & & $50 \%$ & $50 \%$ \\
\hline
\end{tabular}

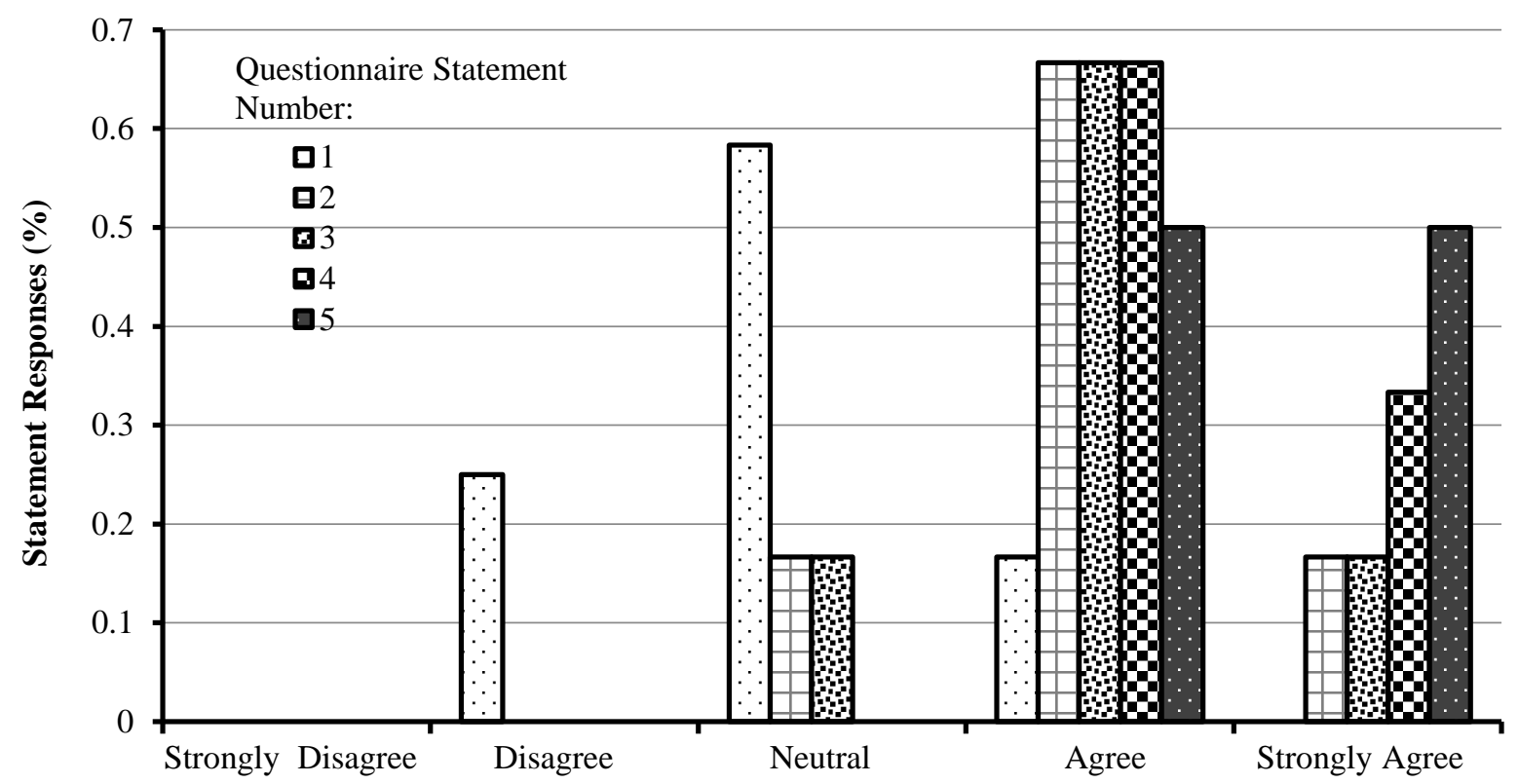

Figure 1: Questionnaire responses from engineering graduate students who attended the career development seminar (questionnaire statements are shown in Table 1).

\section{REFERENCES}

[1] Statistics Canada, "Historical statistics of Canada: Education," Statistics Canada, Ottawa, 2017.

[2] D. E. Bill Burnett, Designing Your Life: How to Build a Well-Lived, Joyful Life, New York City: Random House, 2016.
[3] S. G. Niles, "Career Flow: A hope-centered model of career development," Journal of Employement Counseling, vol. 48, pp. 173-175, 2011.

[4] L. Peto and C. Geddert, "Using Career Education to Help Students Build and Articulate Employability Skills," in Canadian Engineering Education Association, Canmore, AB, 2014. 